\title{
ПРОБЛЕМЫ ФОРМИРОВАНИЯ НАЦИОНАЛЬНОЙ ИДЕНТИЧНОСТИ В США И РОССИИ
}

Аннотация. Объектом исследования являются проблемы формирования национальной идентичности в США и России. Предметом выступает специфика генезиса, формирования и функ-ционирования нации в США и России. Целью исследования является анализ особенностей и закономерностей формирование национальной идентичности. В соответствии с целью можно выделить следующие задачи:

1. Рассмотреть такое явление как формирование нации, выявить при-чины и факторы которые помогают её сформировать.

2. Показать спещифику формирования нации в России и США. З.Выявить проблемы нациестроительства в России и США

3. Провести анализ, выявить общие закономерности, проблемы и тенденции в в развитии нациестроительства в США и РФ.

Ключевые слова: политология, идентичность, этнос, национализм, иммиграция, государство, Российская Федерация, США, проблематика, генезис.

$\mathrm{B}$ опрос о формировании национальной идентичности стоит в нашей стране более 20 лет. В преамбуле к Конституции говорится о «многонациональном народе Российской Федерации» 1 . Как было нами отмечено, называть этносы «нациями» не совсем верно, так как под нацией обычно понимается сообщество граждан государства.

По мнению Валерия Тишкова, использование неправильной терминологии, явилось фактором, который привел к тому, что российское государство было подвергнуто испытаниям этнического национализма, в том числе и вооруженному сопротивлении со стороны так называемой самоопределяющейся чеченской нации ${ }^{2}$.

Академик Тишков полагает, что правильнее было бы воспользоваться концепцией Ильина и называть не «многонациональным народом», а «многонародной» ${ }^{3}$ нацией, но поскольку «коней на переправе не меняют», то он считает необходимым более активнее и последовательней утверждать «нацию» и «национальное» в общегосударственном и гражданском смысле, при этом сохранив практику использования данного понятия в этническом смысле.

\footnotetext{
Конституция РФ с комментариями Конституционного Суда РФ М.: Инфра-М, 2006.

2 Тишков В.А, Тишков В.А. Российская нация и российские национальности. Электронный ресурс // Валерий Тишков // URL http://www.valerytishkov.ru/engine/documents/ document1257.pdf

3 Тишков В.А. О российском народе и национальной идентичности в России. Электронный ресурс // URL: http://www. valerytishkov.ru/cntnt/publikacii3/publikacii/o_rossisko.html
}

Для того чтобы существенно облегчить задачу нациестроительства в Российской Федерации необходимы собирательные образы страны и народа. Все страны мира, как правило, имеют некий самообраз, что позволяет им не ставит себя ниже соседей, помогает гражданам страны нормально чувствовать в социально-психологическом смысле, обеспечивает преданность и сплоченность населения. Так, по мнению Тишкова: »если у большинства населения нет схожего и позитивного представления о стране и о государстве, тогда и нет этого государства» ${ }^{4}$.

Также для обеспечения становления российской нации необходимо отходить от старых советских определений на тему, что есть народ, нация, национальное государство. Как было уже нами сказано, многие десятилетия термин «национальное» понимался исключительно в этнических или этнокультурных категориях. Даже советские юристы международно-правовые документы и декларации о самоопределение народов и так далее излагали в этническом смысле, хотя о каком едином этносе может идти речь в Индии ,Китае, Испании и так далее, тут необходимо отметить ,что согласно международному праву под термином» народ понимается территориальное сообщество ${ }^{5}$

Для этнонационалистов Россия не существует как национальное государство, так как они размышляют узкоэтнически, так, Рамазан Абдулати-

\footnotetext{
4 Тишков. В.А Российская нация как состоявшийся проект [Электронный pecypc] ] // URL: http://www.valerytishkov.ru/ cntnt/na_sluzhbe/v_obshestv2/rossijskay.html

5 Там же.
} 


\section{Международные отношения International Relations}

пов считал, что «если у русской нации нет «своей республики», то нужно её создать» ${ }^{6}$ Рамазан Абдулатипов писал: »у русских нет, как у других российских наций, своего отдельного, «республиканского» голоса в государственном управлении и в законодательстве».

Другие же этнонационалисты вроде Сергея Глазьева предлагают иной путь решения проблемы, он предлагает «объявить всех жителей страны русскими» ${ }^{7}$.

Полагаем, что данные идеи имеет потенциальную опасность для страны, так как если предположить создание русской республике, то не совсем понятно на территориях какого субъекта или субъектов будет расположена данная республика, учитывая тот факт, что согласно данным последней переписи русские составляют $80 \%$ населения ${ }^{8}$, также надо понимать, что такие попытки не только не решат проблему, но и серьёзно её ухудшат, так как в России проживают более 100 различных этносов и есть республики где малочисленные этносы составляют подавляющее большинство, что естественно может привести к новой волне сепаратизма в нашей стране.

Примерно такими же высказываниями пестрят различные печатные издания, которые утверждают: «Давайте исходить из реальностей. Россия никогда не была национальным государством. И не существует такой - российской нации... Мы говорим о русской нации, о русском (российском) национальном государстве (а некоторые вопреки всем правилам логики и здравому смыслу даже говорят о России как о нации), но поскольку на самом деле ничего этого не было и нет, мы вынуждены делать разного рода оговорки... Россия была и есть то, что можно назвать территориальной империей. Территориальная империя как форма государственного устройства господствовала в мире и в Европе на протяжении столетий, причем Россия - единственная европейская территориальная империя, сохранившаяся до наших дней» ${ }^{9}$.

Также необходимо упомянуть о проблеме мигрантов в России. В 2002 г. Россия вышла на второе место по числу иммигрантов, согласно оценке

\footnotetext{
6 Там же.

7 Там же.

8 Итогивсероссийскойпереписи населенияза2010г. Т.4.ч. 1// Всероссийская перепись населения 2010 г. // URL: http:/ www.gks.ru/free_doc/new_site/perepis2010/croc/Documents/ Vol4/pub-04-01.pdf

9 Григорьев О. Россия никогда не была национальным государством. «Главная тема», июль-авг. 2005. с. 54-57.
}

экспертов ООН, их более 13 млн человек ${ }^{10}$, что составляет около 9\% от общего числа населения. Так, руководитель ФМС РФ Константин Ромодановский сообщил, что за счет миграции удалось покрыть $71 \%$ естественной убыли населения РФ.

А в «докладе о международной миграции 2012», составленной экспертами ОЭСР, утверждается, что численность временных трудовых мигрантов в России вдвое больше, чем в США ${ }^{11}$, при этом надо учитывать что Америка считается одной из самых неблагополучных стран в этом отношении

Основная проблема иммиграции в России заключается в следующем:

1. Иммигрантам присущ совершенно другой культурный код, который отличается от культурного кода большинства населения России. Нередко, иммигранты выделяются вызывающим поведением, что естественно ведет к отторжению и неприятию их коренным населением.

2. Незнание государственного языка РФ, которое приводит к возникновению непонимания между коренным населением и мигрантами. Также стоит отметить, что иммигранты предпочитают селиться компактно, в результате чего отсутствует положительная динамика интеграции их в российское общество.

3. Большое количество преступлений совершается мигрантами. Так, согласно данным СК РФ в первом полугодии 2011 г. 1/7 убийств в столице и почти половина изнасилований совершается нелегальными мигрантами ${ }^{12}$. Естественно такие факты лишь нагнетают межэтническую напряженность в стране.

В контексте всего сказанного мы считаем, чтобы решить проблему построение российской нации, нужно сделать на наш взгляд следующее:

1. Поддержка русского языка, который имеет статус государственного и одновременно является скрепляющим языком для всех этносов России. В этой связи необходимо отметить, что в различных субъектах РФ существуют региональные языки, которые имеют статус госу-

\footnotetext{
10 Доклад о международной миграции за 2002 г. [Электронный ресурc] // OOH URL: http://www.un.org/esa/population/ publications/ittmig2002/ittmigrep2002.htm

11 Русский обозреватель. В России самое большое количество нелегальных мигрантов. [Электронный ресурс] // Русский обозреватель // URL http://www.rus-obr.ru/days/18751

12 Росбалт. СК: Половина изнасилований в Москве совершены гастарбайтерами [Электронный ресурс] // Росбалт // URL: http://www.rosbalt.ru/moscow/2011/07/20/870977.html
} 
дарственного, как например, в Татарстане ${ }^{13}$, в результате получается то, что этносы, для которых данный язык не является родным, вынуждены его учить. На наш взгляд изучение региональных языков нужно сделать добровольным делом, но при этом всячески мотивировать на изучение данного языка и приобщение к данной культуре как к российской культуре.

2. Необходима выработка и поддержка общероссийских духовно-нравственных норм, которые будут поддерживаться путём создания различных художественных и кинематографических образов ориентированных на массовую публику.

3. Сформированная и продуманная поддержка традиционной российской культуры, путём популяризации литературы, фольклоры, живописи, кино и так далее. Тут необходимо отметить и особый статус русского языка и русской культуры, как скрепляющего ядра. Но необходимо понимать, что нельзя допускать перегибы и привилегии по отношению к какому-либо этносу, так как это может привести к негативному восприятию у других этносов, к росту экстремизма, сепаратизма и так далее.

4. Создание и оформление некого пантеона национальных героев с древнейших времен до наших дней, празднование памятных дат на должном уровне.

5. Создание и формирование общей национальной истории, в которой не будет допустимо «обливание грязью» или фальсификации какоголибо периода нашей истории, граждане должны чувствовать связь времен, общество должно быть едино как в прошлом, так и в настоящем и будущем.

6. Необходима популяризация армии и идеи защиты Отечества. Армия должна стать одним из важнейших институтов становление и социализации личности.

7. Борьба с коррупцией. Борьбе с коррупцией должен быть придан особый, важный статус, так как часто национальные конфликты возникают, когда граждане одного этноса коррупционным путём получают привилегии над гражданами другого этноса. В качестве таких примеров, можно привести события на Манежной площади.

8. Необходима введение частичной цензуры как в СМИ, так и в интернете, так как очень часто различные общественные, политические, рели-

13 Республика Татарстан. Конституция (1992). Статья 8. Конституция Республики Татарстан: с изм. и доп. на 1 окт. 1997 г. Казань, 1997. гиозные, научные деятели позволяют себе высказывать различные резко отрицательные высказывания в сторону различных этнических, социальных, конфессиональных и иных групп, что ведёт к обострение ситуации в стране и «подливает масло в огонь».

9. Осознание территории России, как единого целостного суверенного и демократического государства, включающие в себя разнообразные регионы.

10. Пропаганда и активное продвижение Конституции РФ и других государственных правовых норм среди различных слоев населения.

11. Придание русскому народу статуса государствообразуюшего. На наш взгляд, необходимо придания статуса государствообращующего народа русскому народу, ведь если мы проанализируем опыт Российской Империи и СССР, то мы можем сделать вывод о том, что русский народ ,русская культура и русский язык всегда выступала в качестве ядра вокруг которого сплачивались остальные народы России.

12. Равенство административно-территориальных субъектов РФ. На наш, взгляд необходимо уравнять все территориальные субъекты, так как разный административно-территориальный статус создает неравенство народов России и нагнетает этническую напряженность в стране, вызывая негативную реакцию у доминирующего этноса страны. Так как он не имеет статус государствообрающего народа и у него отсутствует своя административно-территориальной единица в формате республики, это все дает плодотворную почву для различных право-радиальных движений.

13. Ужесточения миграционного законодательства, а также ответственности за нарушение административного и уголовного права для иммигрантов, совершенно недопустимо, когда иммигранты приезжающие в страну, начинают вести себя вызывающе, нарушают административное и уголовное право, провоцируют негативное отношение к себе у коренного населения, в этой связи необходимо ужесточение ответственности за такие деяния, чтобы лица уличенные в нарушении миграционного, административного и уголовного законодательств депортировались из страны и им запрещалось пожизненно въезжать в страну.

14. Необходимо внести изменения в ФЗ «О гражданстве РФ», так как в последнее время сложилась практика, когда иностранные граждане, преимущественно из Средней Азии, едут ро- 


\section{Международные отношения International Relations}

жать в Россию ${ }^{14}$, так как согласно закону ${ }^{15}$ люди рожденные на территории РФ могут претендовать на гражданство России, что дает возможность детям таких родителей становится гражданами РФ, а их родители становятся гражданами в упрощенном порядке. Граждане, которые имеют диаметрально противоположные социальные, культурные и языковые установки, не интегрируются в российское гражданское общество.

Bсе эти положения необходимо проводить в жизнь комплексно, продуманно и последовательно и это, без сомнения, окажет положительное влияние на процесс нациестротельства в Российской Федерации и позволит сформировать «нацию наций» ${ }^{16}$.

Проанализировав проблемы и пути их решения, которые стоят перед Россией по формированию российской нации, перейдём к рассмотрению современных проблем, которые встают перед американской нацией.

В последние 20 лет в мире все более и более актуальная встаёт национальный вопрос так В. Иорданский пишет: «В масштабе человечества национальный вопрос встает в противоборстве двух тенденций. Обе они объективны, обе реализуются в воле, поступках миллионов людей. Первая - в движении наций к самоопределению и независимости, вторая, напротив, - в стремлении к образованию крупных полиэтнических общностей, к формированию мощных “супернаций”, где органично были бы соединены этносы, различные традиции и культуры ${ }^{17}$ ». Эта тенденция затронула и США.

Современная проблема национальной идентичности в США началась после того, как они пересмотрели свою концепцию «плавильного котла». В 1964 г. был принят «Акт о гражданских правах», а в 1965 г. «Иммиграционный акт», который положил начало массовой иммиграции, а уже в 1968 г. был принят «Акт о двуязычном образовании». В результате были введены двуязычные образовательные программы, в основном, испаноязычные, что затормаживало, если не препятствовали их ассимиляции и соответственно интеграции в американскую нацию.

\footnotetext{
14 Комсомольская правда. Россия превращается в роддом для гастарбайтеров. [Электронный ресурс] // Комсомольская правда // URL: http://www.kp.ru/daily/25931/2880227/

15 Ф3 от 31.05.2002 № 62-Ф3 (ред. от 28.06.2009) «О гражданстве Российской Федерации». Глава 2. Статья 12.

16 Тишков В.А Российская нация и российские национальности. с. 11.

17 Иорданский В. Глобальный этнический кризис, или сумерки разобщенности // МЭиМО. 1993. №12. С. 84.
}

Другая проблема состояла в том, что испаноязычных иммигрантов стало довольно много и они преимущественно селились компактно на юге, тем самым образовывая диаспоры, которые, в результате принятия акта 1968 года почти невозможно было ассимилировать.

Благодаря акту 1965 г., в страну в 1970-е легально въехало около 640 тысяч человек, в 1980-е их количество увеличилось более чем в 2 раза и составило 1656000 человек, а в 1990-е количество переселенцев из Мексике достигло 2249000 человек, в результате чего за 30 лет доля мексиканцев в легальной иммиграции возросла с $14 \%$ до $25 \%{ }^{18}$, а ведь не надо забывать о нелегальных иммигрантах число которых значительно больше, чем легальных иммигрантов. Так, согласно оценкам Пограничной гвардии количество нелегальных иммигрантов из Мексики выросло с 1600000 человек в 1960-е годы до 11900000 человек в 1980-е и до 12900000 человек в 1990-е годы. Международная мексикано-американская комиссия оценивает ежегодное количество нелегальных иммигрантов в 105000 человек; служба иммиграции и натурализации приводит в своих отчетах цифру в 300000 человек ${ }^{19}$.

Хантингтон утверждает, что: «нелегальную иммиграцию можно с полным правом назвать мексиканской иммиграцией ${ }^{20}{ }_{\text {». }}$

Мексиканская иммиграция отличается от всех остальных одной важной особенностью, мексиканцы прибывают из страны которая имеет непосредственные территориальные границы с США, они прибывают на территорию, которую вполне могут считать своей, так как почти весь Техас, НьюМексико, Аризона, Калифорния, Невада и Юта принадлежали Мексике и былы захвачены у неё в ходе Техасской войны за независимость и последующей за ней Мексикано-американской войны. Питер Скерри писал: «В отличие от прочих иммигрантов, мексиканцы прибывают в США из страны, расположенной по соседству, из страны, потерпевшей военное поражение от Соединенных Штатов, и селятся

18 Цитата по С. Хантингтон. Кто мы? С.350.

Roger Daniels, Coming to America: A History of Immigration and Ethnicity in American Life (New York: HarperCollins, 1990). p. 129,146 .

19 Цитата по С. Ханингтону. Кто мы? С. 354.The Economist, 20 May 1995. p. 29; New York Times, 3 June 1995, p. B2; Immigration and Naturalization Service study, reported in New York Times, 8 February 1997, p. 9; INS study, reported in Boston Globe, 1 February 2003, p. A8; Census Bureau figure reported in Washington Post, 25 October 2001, p. A 24

20 Хантингтон С. Кто мы? : вызовы амер. нац. идентичности / пер. с англ. А. Башкирова. М.: АСТ, 2008. С. 354. 
в регионе, на который когда-то распространялась юрисдикция их родины. Поэтому американцам мексиканского происхождения присуще чувство нового освоения родной земли, отсутствующее у прочих иммигрантов» ${ }^{21}$.

Делая выводы по всевышесказанному, считаем необходимым отметить, что главная угроза национальной идентичности в США - это мексиканцы. Чтобы решить проблему угрозу национальной идентичности США, нужно сделать следующее:

1. Необходимо отменить «акт о двуязычном образовании» от 1968 г., ибо он таит в себе одну из главных угроз для американской идентичности, так Хантигон считает, что « язык...это основа общества» ${ }^{22}$.

2. Необходимо принять закон об общем обязательно образовании для иммигрантов и их семей, так всего $24,3 \%{ }^{23}$ мексиканцев имели среднее образование. Образование является мощнейшим институтом для ассимиляции и интеграции различных этнических групп в американскую нацию.

3. Ужесточить миграционное законодательство. В случае правонарушение иммигрантом законодательства страны необходимо депортировать его вместе с членами семьи и запретить пожизненно въезжать на территорию США.

4. Ужесточение законов. Необходимо вводить уголовную ответственность для тех работодателей кто берёт на работу нелегальных иммигрантов.

5. Изменить закон о получение гражданства. Согласно этому закону любой человек родившийся на территории США автоматически становится её гражданином, даже те кто родился в семье нелегальных иммигрантов. Благодарю этому закону гражданами в 2009 г. стало 350 тысяч человек ${ }^{24}$.

6. Ужесточить процесс натурализации. Для граждан, которые претендует на гражданство США ввести обязательное условие отслужить в армии. Так как армия является важнейшим институтом в процессе интеграции человека в нацию.

21 Цит.: по С. Хангтигтону. с. 361. Peter Skerry, Mexican Americans: The Ambivalent Minority (Cambridge: Harvard University Press, 1993), p. 289 also p. 21-22.

22 Хантингтон С. Кто мы?: вызовы амер. нац. идентичности / пер. с англ. А. Башкирова. М.: АСТ, 2008 С. 250.

23 Там же. с. 366.

24 Российская газета. Нелегала оставят без игрушки. [Электронный ресурс] ] // Российская газета // URL: http://www. rg.ru/2011/05/06/igrushki.html
Проанализировав процессы протекающие в России и США, проведем сравнительный анализ проблем в формирование идентичности в США и России:

1. Нелегальная иммиграция. Для России и для США весьма актуальны проблемы нелегальной иммиграции, Российская Федерация и Америка занимают лидирующие места по количеству легальных и нелегальных иммигрантах

2. Отсутствие сформированной политики нациестроительства.

В США, как и в России отсутствуют эффективная политика нациестроительства, что обусловлено различными причинами, в США это связано с тем, что они отошли от модели «плавильного котла» и перешли к концепции мультикультурализма, а в России это связано с распадом СССР и с довольно вялыми попытками сформировать эффективную политику нациестроительства в течение довольно продолжительного времени. Стоит отметить, что проблеме нациестроительства в России начали уделять внимание только в последние годы.

3. Сохранение идентичности иммигрантами и противопоставление их гражданам страны. Большинство иммигрантов сохраняют свою идентичность и не хотят принимать идентичность той страны, в которую приезжают, так как большинство из них предпочитают селиться компактно, в результате чего затрудняется их интеграция в общество страны, а из-за наличия иных ценностей, культуры и менталитета они противопоставляют себя гражданам страны, что создают этническую напряженность.

4. Неприятие иммигрантов гражданами страны. Поскольку большинство иммигрантов въезжают либо находятся на территории страны нелегально, то они не имеют возможности обращаться в правоохранительные органы, боясь быть депортированными на Родину, поэтому работодатели часто нарушают их права, платят им гораздо меньше, чем бы платили гражданам страны, соответственно конкуренция на рынке труда повышается и граждане в низкоквалифицированных отраслях деятельности не могут на равных конкурировать с иммигрантами. Что влечёт за собой неприятия мигрантов населением и усложняет социально-экономическое положение граждан страны, это характерно как и для США, так и для РФ.

5. Получение гражданства по рождению. В России, как и в США набирает популярность поездка в страну с целью родить детей, так как это дает возможность получения гражданства, так как 


\section{Международные отношения International Relations}

нормативно-правовыми актами страны предусматривается получение гражданства, гражданам которые родились на территории государства.

6. Отсутствие эффективной миграционной политики и мер по борьбе с нелегальной миграцией. Для России, как и для США чрезвычайно акту- ально отсутствие эффективных мер по борьбе с нелегальной миграцией, которые позволяет попадать и задерживаться нелегальным мигрантом на территории страны, в результате отсутствия эффективной миграционной политики и пробелы в законодательстве, позволяют легализоваться некоторой категории мигрантов.

\section{Источники:}

1. Конституция РФ с комментариями Конституционного Суда РФ М.: Инфра-М, 2006.

2. Тишков В.А, Тишков В.А. Российская нация и российские национальности. Электронный ресурс // Валерий Тишков // URL http://www.valerytishkov.ru/engine/documents/document1257.pdf

3. Тишков B.A. O российском народе и национальной идентичности в России. Электронный ресурс // URL: http://www.valerytishkov.ru/cntnt/publikacii3/publikacii/o_rossisko.html

4. Тишков. B.A Российская нация как состоявшийся проект [Электронный ресурc] ] // URL: http://www. valerytishkov.ru/cntnt/na_sluzhbe/v_obshestv2/rossijskay.html

5. Итоги всероссийской переписи населения за 2010 г. Т. 4. Ч. 1 // Всероссийская перепись населения 2010 г. // URL: http://www.gks.ru/free_doc/new_site/perepis2010/croc/Documents/Vol4/pub-04-01.pdf

6. Григорьев О. Россия никогда не была национальным государством. «Главная тема», июль-авг. 2005. C. 54-57.

7. Доклад о международной миграции за 2002 г. [Электронный ресурс] // OOH URL: http://www.un.org/ esa/population/publications/ittmig2002/ittmigrep2002.htm

8. Русский обозреватель. В России самое большое количество нелегальных мигрантов. [Электронный ресурс] // Русский обозреватель // URL http://www.rus-obr.ru/days/18751

9. Росбалт. СК: Половина изнасилований в Москве совершены гастарбайтерами [Электронный ресурс] // Росбалт // URL: http://www.rosbalt.ru/moscow/2011/07/20/870977.html

10. Республика Татарстан. Конституция (1992). Статья 8. Конституция Республики Татарстан: с изм. и доп. на 1 окт. 1997 г. Казань, 1997.

11. Комсомольская правда. Россия превращается в роддом для гастарбайтеров. [Электронный ресурс] // Комсомольская правда // URL: http://www.kp.ru/daily/25931/2880227/

12. Тишков В.А Российская нация и российские национальности. С. 11.

13. Иорданский В. Глобальный этнический кризис, или сумерки разобщенности // МЭиМО. 1993. №12. С. 84.

14. Цитата по С. Хантингтон. Кто мы? С.350.

15. Roger Daniels, Coming to America: A History of Immigration and Ethnicity in American Life (New York: HarperCollins, 1990). P. 129, 146.

16. Цитата по С. Ханингтону. Кто мы? С. 354.The Economist, 20 May 1995. P. 29; New York Times, 3 June 1995, p. B2; Immigration and Naturalization Service study, reported in New York Times, 8 February 1997, p. 9; INS study, reported in Boston Globe, 1 February 2003, p. A8; Census Bureau figure reported in Washington Post, 25 October 2001, p. A 24

17. Хантингтон С. Кто мы? : вызовы амер. нац. идентичности / пер. с англ. А. Башкирова. М.: АСТ, 2008. С. 354.

18. Цит.: по С. Хангтигтону. С. 361. Peter Skerry, Mexican Americans: The Ambivalent Minority (Cambridge: Harvard University Press, 1993), p. 289 also p. 21-22.

19. Хантингтон С. Кто мы?: вызовы амер. нац. идентичности / пер. с англ. А. Башкирова. М.: АСТ, 2008 С. 250.

20. Российская газета. Нелегала оставят без игрушки. [Электронный ресурс] ] // Российская газета // URL: http://www.rg.ru/2011/05/06/igrushki.html

\section{References (transliteration):}

1. Konstituciya RF s kommentariyami Konstitucionnogo Suda RF M.: Infra-M, 2006.

2. Tishkov V.A, Tishkov V.A. Rossiiskaya naciya i rossiiskie nacional'nosti. Elektronnyi resurs // Valerii Tishkov // URL http://www.valerytishkov.ru/engine/documents/document1257.pdf

3. Tishkov V.A. O rossiiskom narode i nacional'noi identichnosti v Rossii. Elektronnyi resurs // URL: http://www. valerytishkov.ru/cntnt/publikacii3/publikacii/o_rossisko.html 
4. Tishkov. V.A Rossiiskaya naciya kak sostoyavshiisya proekt [Elektronnyi resurs] ] // URL: http://www.valerytishkov.ru/cntnt/na_sluzhbe/v_obshestv2/rossijskay.html

5. Itogi vserossiiskoi perepisi naseleniya za 2010 g. T. 4. ch. 1 // Vserossiiskaya perepis' naseleniya 2010 g. // URL: http://www.gks.ru/free_doc/new_site/perepis2010/croc/Documents/Vol4/pub-04-01.pdf

6. Grigor'ev O. Rossiya nikogda ne byla nacional'nym gosudarstvom. «Glavnaya tema», iyul'-avg. 2005. S. 54-57.

7. Doklad o mezhdunarodnoi migracii za 2002 g. [Elektronnyi resurs] // OON URL: http://www.un.org/esa/population/publications/ittmig2002/ittmigrep2002.htm

8. Russkii obozrevatel'. V Rossii samoe bol'shoe kolichestvo nelegal'nyh migrantov. [Elektronnyi resurs] // Russkii obozrevatel' // URL http://www.rus-obr.ru/days/18751

9. Rosbalt. SK: Polovina iznasilovanii v Moskve soversheny gastarbaiterami [Elektronnyi resurs] // Rosbalt // URL: http://www.rosbalt.ru/moscow/2011/07/20/870977.html

10. Respublika Tatarstan. Konstituciya (1992). Stat'ya 8. Konstituciya Respubliki Tatarstan: c izm. i dop. na 1 okt. 1997 g. Kazan', 1997.

11. Komsomol'skaya pravda. Rossiya prevrashaetsya v roddom dlya gastarbaiterov. [Elektronnyi resurs] // Komsomol'skaya pravda // URL: http://www.kp.ru/daily/25931/2880227/

12. Tishkov V.A Rossiiskaya naciya i rossiiskie nacional'nosti. s. 11.

13. Iordanskii V. Global'nyi etnicheskii krizis, ili sumerki razobshennosti // MEiMO. 1993. ${ }^{1} 12$. S. 84.

14. Citata po S. Hantington. Kto my? S.350.

15. Roger Daniels, Coming to America: A History of Immigration and Ethnicity in American Life (New York: HarperCollins, 1990). p. 129, 146.

16. Citata po S. Haningtonu. Kto my? C. 354.The Economist, 20 May 1995. p. 29; New York Times, 3 June 1995, p. B2; Immigration and Naturalization Service study, reported in New York Times, 8 February 1997, p. 9; INS study, reported in Boston Globe, 1 February 2003, p. A8; Census Bureau figure reported in Washington Post, 25 October 2001, p. A 24

17. Hantington S. Kto my? : vyzovy amer. nac. identichnosti / per. s angl. A. Bashkirova. M.: AST, 2008. S. 354.

18. Cit.: po S. Hangtigtonu. s. 361. Peter Skerry, Mexican Americans: The Ambivalent Minority (Cambridge: Harvard University Press, 1993), p. 289 also p. 21-22.

19. Hantington S. Kto my?: vyzovy amer. nac. identichnosti / per. s angl. A. Bashkirova. M.: AST, 2008 S. 250.

20. Rossiiskaya gazeta. Nelegala ostavyat bez igrushki. [Elektronnyi resurs] ] // Rossiiskaya gazeta // URL: http:// www.rg.ru/2011/05/06/igrushki.html 